\title{
Fostering Creative Thinking in Freshman Engineering
}

\author{
James F. McDonough, Bruce A. Harding \\ University of Cincinnati/Purdue University
}

Is it possible to successfully implement a design project in the first ten weeks of the first quarter of the freshman year of an engineering program? If it is possible, will it have any effect on the attitude of the students towards the engineering program? The following is a discussion of a program developed for freshman at the University of Cincinnati.

The University College of Engineering is a mandatory co-op program, the first of its kind in the nation. The students are accepted into a specific engineering discipline during the application process. The college contains six departments with ten undergraduate majors. Since students are accepted into a specific program it is possible to identify the Civil Engineering students from the very start of the freshman year. During that first year and prior to the introduction of the Introduction to Engineering class the college had little contact with Engineering freshman, and the departments had no contact with their own majors until the second year.

Difficulty in student retention in the first year of engineering has been well documented. The problem of retention is compounded when future class sizes are projected based on the number of freshman. Retention then becomes the unknown variable. In recent years there has also been a decline in the number of highly qualified high school students entering engineering programs. This decline has made it all the more important to retain those students in the college and hopeful in the program they originally selected.

Although it is possible to change majors after the freshmen year, at UC, a 3.0/4.0 quality point average is required to ensure transfer. Unfortunately this means that those who might decide to transfer programs within the college are among the best of the students. Thus given the need to retain the high quality students and the practicality of maintaining student head count during a period of reduced funding, it was decided to make a frontal assault on the problem.

A course entitled introduction to Engineering was established. This course is taught in the Autumn quarter of the freshman year. At the beginning of its life it was taught to a section of all 500 of the freshman class, with small breakout sections of students meeting several time during the quarter. The breakout sections were focused on the specific majors.

As is often the case there was no readily available faculty to teach the course. The responsibility was delegated to the Associate Dean of Academic Affairs who took the lead in developing and managing the course. Other faculty were used when they could be persuaded to help on a volunteer basis. The original form of this course left a lot to be desired as the students did not get much out of the massive meetings. They did like the smaller gatherings, but overall the course needed more personal contact between students and faculty.

It was about this time that that professor Harding joined the college office while of sabbatical from Purdue University. He brought a fresh approach to the course when he volunteered to lead a small section of the few undecided students from the pre-engineering program housed in the Arts and Science college. He had taught the same concepts at Purdue, although not to students at the very start of their programs. 
In an attempt to introduce creative problem-solving earl y in student's plan of study, a design project was incorporated in the Introduction to Engineering class. The majority of the mass section meetings were eliminated in favor of small sections (20 to 24) grouped together by major plus the section of undecided students. Each recitation section of the class derived a different project. Some project topics were chosen by the recitation instructor, others were chosen by the section as a whole. Because the class is taken by all College of Engineering majors, the projects were designed to be major and gender neutral.

Before classes began, all instructors were taken through a workshop on teaching creative problem-solving. The workshops focused on techniques to stimulate creative thinking and included sample exercises, help on possible topics for a design project and a review of support documentation. Each instructor was then free to devise a project theme or open it up to their class for selection. Once the project was identified, each instructor broke their class up into small teams. Teams were to compete for the 'best' solution to the design parameters. The remainder of the class served as the customer of the idea. 'Best' varied among sections, but usually was based on a group presentation to sell their idea to the rest of the class. In some sections, the class voted on best solutions. All teams were required to produce a poster for a poster session which was displayed throughout nearly all halls of the Engineering buildings. It was well received by faculty and students alike who had an opportunity to view the work of other classes and groups. Some instructors also required a written report by each team.

Because of the limited time available for the design project, it was determined that the project could be accomplish by breaking the exercise into several components. Furthermore, the project evaluation was then based on as many as four components: written Report, oral Presentation, ranking of presentations and team peer evaluation. These components were:

\section{Idea generation}

Small group dynamics

The engineering design process

Presentations and reports

Creativity and alternate solutions

Definition of problem statement

\section{Zeroing-in}

Brainstorming

Analysis of options

Using decision matrices

\section{Selling the Idea to the Audience (customer)}

Recognizing that these students were in fact freshmen, depth of instruction within the outline was abbreviated to include only the major points. For example, in covering small group dynamics, students were introduced to methods for dealing with conflict within their group. They were mentored as to techniques for drawing shy people out, diverting bullyism, etc. When introducing the engineering design process, customer needs, creative alternatives and objectivity in selecting 'best' solution were emphasized. 
Yes, it is possible to use design projects in a very early course. The students are creative and accept the challenge. They understand their limitations but are able to produce creative solutions to the problems. Typical student responses to the project include:

- "Great, it was fun to solve a real problem."

- "This idea was rather fun and interesting to do. It made us think a little."

- "Project was decent- Need more time to get organized. Maybe do it earlier because work piles up at the end of the quarter. Enjoyable."

- "I believe that if given more time the project would be more enjoyable. But it was fun to design and work on this project."

- "Good project, but I'd give a few more weeks to work on it."

About $70 \%$ of the students liked the design project, although they had comments regarding the difficulty getting the team together, the amount of time it took or the lateness in the quarter when they began the project. The faculty were also very impressed with what the students were able to accomplish given that they had no "design" courses.

Another very important outcome was the students response to the question "Do you feel like you area part of the college of engineering.'?" Over $90 \%$ of the students answered that they agreed, or strongly agreed that they felt like a part of the college of engineering. Although it is too early to measure the retention question, the students were drawn into the college, and could not complain about that as an issue.

Another critical issue has arisen as the course continued over the last three years. The faculty are reluctant to continue to volunteer to teach the course since they do so as an overload. Although it does not take as much time as a three credit course, it does take time. There is no "credit" associated with the teaching of this course and there is little incentive to continue to teach the course. The faculty who taught this course care deeply about the students but their primary driving force continues to be to do scholarship of discovery and to obtain funding for that work. They feel that if they do not succeed in that arena, they will not be able to help the students in the long run. As a result, the course is now in jeopardy - an ironical twist, just as other institutions are beginning to recognize the importance of an effective Introduction to Engineering class.

James F. McDonough has been an active member of ASEE, serving in his section, zone and Board of Directors. He has served as chairman of the Civil Engineering Division and of the New Engineering Educators Committee. In 1986 McDonough was Chairman of the ASEE Annual Conference held in Cincinnati. In 1991 he was honored as the Distinguished Engineer of the Year by the Technical Societies Council of Cincinnati and also named an ASEE Fellow. In 1993, he was selected as an ASEE Centennial Medalist and received the George Wadlin Award for Distinguished Service by the Civil Engineering Division.

During his 30 years at Cincinnati, McDonough's teaching and scholarship have been recognized through numerous awards and publications. He is a recipient of both the ASEE Outstanding Young Faculty Award and the ASEE Award for excellence in engineering instruction. McDonough also served on the Ohio State Board of Registration for Professional Engineers and Surveyors. He spent two years from 1969-71 at the College of Engineering in Kabul, Afghanistan.

Bruce A. Harding is Professor of Mechanical Engineering Technology at Purdue University. He has served in industrial capacities with Olin Mathieson, Westinghouse and IBM. Within ASEE, Harding has been an active contributor; having served in local, section, zone and national offices. He is currently an ASEE Campus Representative and the ERM Division Vice-Chair for Programs. Harding is an active industrial consultant and workshop leader and has authored numerous papers, technical reports and articles for ASEE, SME, ASME, ASM, NCGA and ISA. He is chair of ASME/ANSI Y 14.40, active on other ASME/ANSI Codes and Standards committees, and has held leadership positions in other organizations. At Purdue he has been the course coordinator for several courses, teaches manufacturing design and specifications topics and has served as principal investigator for funded research. 
In developing creativity and alternate solutions, students were given quizzes with very open-ended solutions. An example quiz would be presenting the followwing illustration on an overhead transparency with the verbally stated question, "how many squares do-you see?"

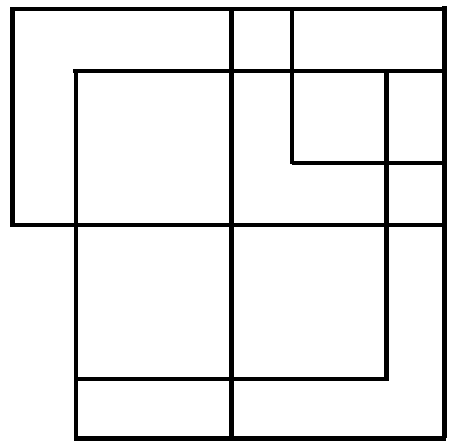

Most students would then busily count the number of squares on the overhead. A few creative ones, noting that the verbal question DID NOT ask how many squares are there on the screen, would start to count all square within sight (walls, floor tiles, etc.) - the creative solution. After several similar exercises, they all began to see that there could be less obvious possibilities when searching for solutions.

When brainstorming, they used classical techniques - rapid-fire solutions, no criticism of others' ideas, combining ideas, etc. When using a decision matrix, they rated their ideas by criteria they felt important to the "selling" of their solution to the remainder of the class. The following is an example decision matrix a class derived to rate possible solutions for the problem statement, Develop a method to protect a bicycle from vandalism AND theft on-campus.

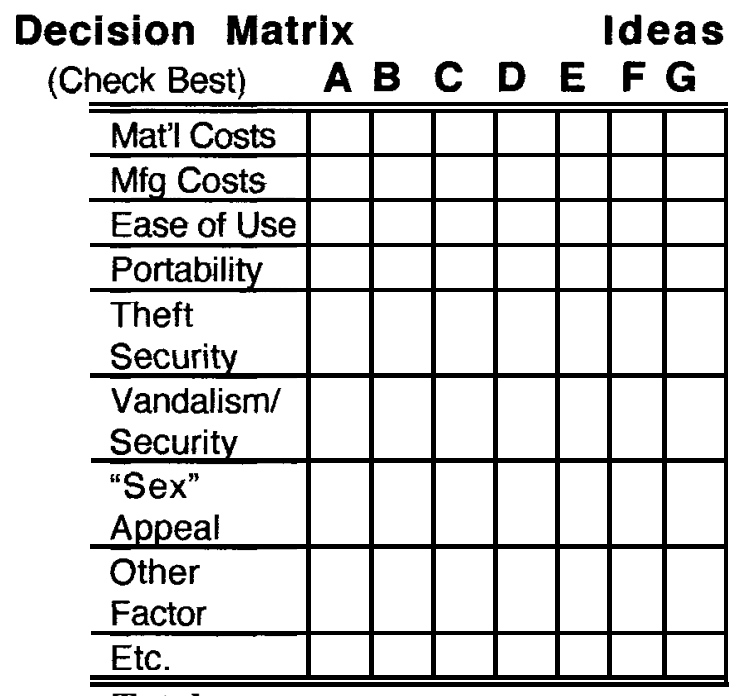

\section{Total}

It should be noted that the decision matrix above was used with the understanding that first-quarter freshmen typically do not have the technical background, time or experience required to definitively answer or even research some of these variables in the matrix. Thus broad estimates were allowed. Even still, a number of teams were motivated to the point that they undertook significant research and development efforts in producing prototypes, mock-ups and market comparisons.

In total, this course has now been offered three times in the manner described and has generated the following conclusions. 